\title{
The CNR Continues to Grow; The Editorial Board Keeps Pace
}

\author{
L. Solymosi
}

Received: 13 January 2014 / Published online: 23 January 2014

(C) Springer-Verlag Berlin Heidelberg 2014

In 2005, our journal found itself in a time of crisis. Many had already written off the 15 -year-old periodical and were calling for its discontinuation. However, some of us could not accept this. We decided to take a risk, and introduced extensive changes in an attempt to revitalize the journal. Klinische Neuroradiologie went international and became the English-language publication Clinical Neuroradiology. Since 2007, all scientific articles published in CNR have appeared in English.

No one among us could predict how well the journal would be accepted by the international neuroradiological community. The years following the initial transition saw us battling with low submission rates, but Clinical Neuroradiology was subsequently accepted by international readers. The number of submissions still continues to increase today.

The logical consequence of our continued success was that we could be more selective in terms of that which we chose to publish. This improved the quality of the journala fact borne out by the continual improvement of our Impact Factor since 2010.

All this led to an enormous increase in the demands placed on our editing staff, and we eventually arrived at the point where our resource capacity was critically stretched. We ran the risk of no longer being able to process submissions in time, of not being able to complete review processes

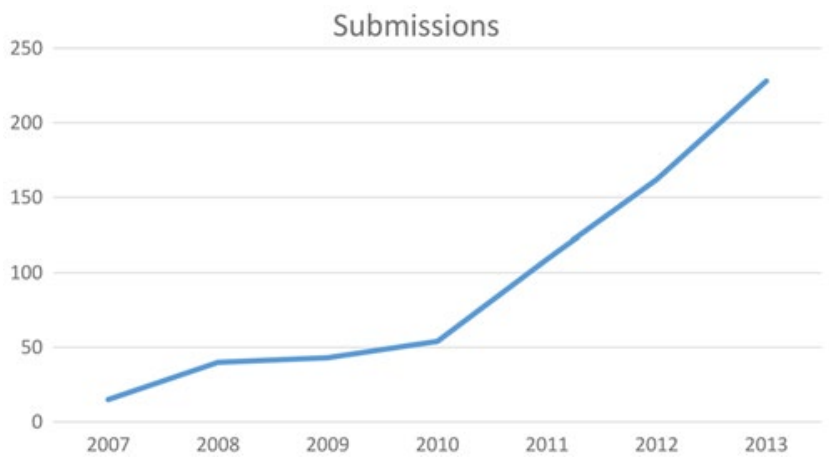

within the previous, acceptable timeframe or to an appropriately high level of scientific quality. This endangered the acceptance and esteem of our journal, and we thus decided to expand the editorial board. The names of our three new colleagues are now to be found on the $C N R$ title page. I would like to take this opportunity to welcome our new editorial board members and thank them for their readiness to volunteer their expertise to $C N R$.

We hope that this important step will enable us to maintain, or even improve, the quality of our journal. Please support Clinical Neuroradiology and its editorial board in your role of assiduous author or critical but fair reviewer.

L. Solymosi $(\bowtie)$

Department of Neuroradiology, University Würzburg,

Würzburg, Germany

e-mail: solymosi@neuroradiologie.uni-wuerzburg.de 